\title{
Visual accountability
}

\section{Daniel Neyland and Catelijne Coopmans}

\begin{abstract}
In this article, we draw attention to the way in which accountability relations are manifested in and through the use of visual evidence. Through their status as representations of what is the case, evidentiary visual images frequently provide a basis for giving accounts and for raising questions regarding distributions of accountability. At the same time, and in a similar manner to numbers (Munro, 2001), such images become part of organized relations of accountability that can be noted as having 'hailing' effects: they call for and prefigure a certain kind of response and dispersing of responsibility. Here we examine how the use of visual evidence is embedded in discursive and material practices that variously create or inhibit possibilities for questioning, or interrogating, this evidence. Drawing on elements of ethnomethodology and actor-network theory, we use 'interrogation' as the basis for depicting a three-part analytical schema focused on opening up, closing down and temporality to explore how visual accountability is worked out in surveillance, traffic management and breast screening images.
\end{abstract}

Keywords: accountability relations, visual evidence, interrogation, social organization of work, ethnomethodology, actor-network theory

\section{Introduction}

Recent years have seen a heightened concern with accountability. It appears that organizations (such as publicly funded bodies, political parties, police forces and large corporate entities) and everyday activities (from shopping under CCTV cameras through to buying a ticket for a flight) are ever more likely to be held to account; and that we are witnessing an increase in both techniques of accountability (including auditing, measuring, benchmarking, testing, etc.) and demands made for certain types of organization to be accountable (as in demands for greater transparency; Neyland, 2007). ${ }^{1}$

This paper deals with the treatment of visual evidence as a focal point of accountability work in organizational practice. It attempts to make sense of situations in which (1) images are presented as evidence (that is, they are made part of an effort to settle a particular matter), (2) the evidential certainty of images is opened (sometimes reopened) for questioning or resistance to questioning is articulated, and (3) through these ongoing activities, images are by John Wiley \& Sons Ltd., 9600 Garsington Road, Oxford OX4 2DQ, UK and 350 Main Street, Malden, 02148, USA. 
invested with the ability to organize accountability relations. In such situations, images are articulated together with, and as part of, sets of relations that establish what course of action needs to follow from the developing understanding of their nature and status as evidence. This happens, for example, through establishing who (or what) can be held to account for image quality, through locating relevant features in the image, and through determining when and to whom visual evidence is presented and circulated.

In social theory, accountability and the visual are frequently seen as particularly intertwined. The use of the term 'account-able' in ethnomethodology, for example, already means both observable and reportable: it refers to 'situated practices of looking-and-telling' (Garfinkel, 1967: 1). In Foucauldianinspired analyses, visibility is noted as central to the disciplining of people (eg through surveillance: Foucault, 1977, 1980; Cooper, 1993; cf. Yar, 2003) as well as processes or practices (eg through enterprise resource planning software: Quattrone and Hopper, 2006). Practical and metaphorical slippage between making things visible, making them count and instituting accountable ways of dealing with them, indicates this intertwining of the visual and accountability. In relation to such familiar repertoires, this paper will suggest that an important, but under-researched, aspect of visual accountability are the practical arrangements in which visual evidence becomes (or is inhibited from being) subject to interrogation. 'Interrogation' is often associated with the questioning of persons ('esp. closely or in a formal manner', Oxford English Dictionary) ${ }^{2}$ however, we use it here in the more general sense of 'examination by questions'. Where visual images are presented and treated as evidence, it is not just what they show, but also their capacity to show some thing - their status as a persuasive, definitive record - that may, or may not be, contested. By seeking to redistribute the accountability relations upon which the status of a visual image is premised, acts of interrogation make such relations apparent.

The import of working towards a repertoire for studying visual evidence in conjunction with the distribution of accountabilities is at least twofold. First, it lies in recognizing how forms of visual evidence such as photographs, video records, medical images and visualizations produced with scientific instrumentation 'enter into accountability relationships' (Munro, 1996: 2, emphasis added) just like output charts, budget reports and other numerical accounts (Munro, 1996). Since such images are made part of an effort to settle a particular matter, they become ingrained with the material arrangements and practices in and through which relations of holding and being held to account unfold, are sustained or are altered. Studying these arrangements and practices remains a powerful way for sociologists to understand, map and critique different conceptions of agency (Callon and Law, 2005). While this first point speaks to concerns with accountability, the paper also contributes to the sociological study of visual evidence. Through the influence of science and technology studies and cultural studies, it has become a commonplace to say that, no matter how unassailable a photograph or other piece of visual evidence may seem, it can always be deconstructed as in some way ambiguous (supporting 
multiple and even opposing claims), or partial (putting forward a particular point of view). In this paper, we offer a subtle development of that point: how visual evidence is treated, and whether or not it becomes subject to attempts at deconstruction, is not a simple matter of, for example, in whose interest it is to treat visual evidence as stable or unstable, but is the upshot of the arrangements governing the production, circulation and contestability of such evidence. In sum, examining organizational accountabilities and visual evidence together can produce refinements in the sociological conceptualization of both fields of enquiry.

In what follows, we will start by suggesting that the sensibilities of both ethnomethodology and actor-network theory offer useful starting points for an exploration of visual accountability. Ethnomethodology orients us toward the moment-to-moment sense-making that displays the methods through which social order is 'done', whereas actor-network theory focuses our attention on the relational organization and distribution of material effects and ontological difference. Drawing on these two approaches, as well as the synthetic sociological contributions to the study of accountability made by Munro (1996, 2001, 2004), we develop a repertoire for studying visual evidence in conjunction with the distribution of accountabilities - a repertoire that centres on the notion of 'interrogation'. We then explore how visual accountability operates in practice on the basis of three empirical studies: one on surveillance images, one on traffic management and one on breast screening. These allow us to elaborate how particular organizational arrangements appear to open up or close down possibilities for interrogating (previously settled) features of visual evidence. The distribution of accountability relations is made prominent and contentious through these processes of opening up and closing down. In addition, these processes sensitize us to the temporal dimension of interrogation, namely the way in which the use of visual evidence is meshed with attempts to project the basis for organizational action back to the past, onto the present and into the future.

\section{Accountability, visual evidence and organization}

Scott and Lyman (1968: 46) define 'accounts' as 'statements made to explain untoward behavior and bridge the gap between actions and expectations'. The implication is that an account is offered on a specific occasion during which we feel called to respond; these responses, according to Scott and Lyman, tend to take the form of excuses (accepting that one has committed the action for which one is being held to account, but denying full responsibility) or justifications (accepting that one has committed the action, but asserting its 'positive value in the face of a claim to the contrary'; 1968: 51). By contemporary standards, this treatment of accounts is rather limited. Munro (1996:2) argues that the study of accounts and accountability should move 'between accounts as stories, explanations and reasons for conduct on the one hand and accounts 
as coded representations, records, often in the form of numbers, on the other hand'. While the first understanding of accounts roughly maps onto Scott and Lyman's definition, the second one opens the door to examining the material orderings in which the production and consumption of accounts is instantiated. Each of these two senses of account has an effect on, and pre-figures, the other. A negative variance in a budgeting process, for example, is a situation in which 'it is numbers themselves [rather than a human agent] which seem to "call" the employee to account' (Munro, 2001: 476). This attention for the materiality of the artefacts with which accounts are produced and consumed resonates with other authors' focus on the work of accountability, such as Strathern's (2000a, 2002) study of the unintended and unexpected consequences of university accountability, and Power's (1997) assessment of the societal consequences of audit rationales. ${ }^{3}$ These authors focus on everyday organizational practices and experiences as pivotal in creating, maintaining and sometimes also changing, a workable sense of what it might mean to hold, and be held, to account. Carrying forward this emphasis on accountability in practice, Neyland and Woolgar (2002) argue that a crucial feature of everyday 'accountability sensitive' work is the identification of relevant audiences for the discharge of accountability. Congruent with this strand of inquiry that aims to locate accountability relations as emerging in and through everyday practices premised on particular distributions of materials and devices, we find that existing literature provides two well-articulated bases for considering visual accountability. One is concerned with the accountable use and interpretation of visual evidence, and the other with how the visual is implicated in the distribution of relations of power and possibilities for action.

The first basis for considering visual accountability - most clearly manifested in ethnomethodological studies of work - is oriented to the question of accountable use and interpretation of visual evidence. Studies on professional vision (Goodwin, 1994) have teased out how those who routinely work with visual evidence learn and in practice manage to 'see' the phenomenon they are asked to assess 'for what it really is'. This involves a merging of visual perception with an understanding of the organizational relations and realities that make certain features worthy of note and attention. For example, Goodwin and Goodwin (1996) studied the work done by airport staff to orient their actions to the aeroplanes they are involved in coordinating. This does not involve straightforwardly looking at aeroplanes, but rather seeing aeroplanes within a web of activity involving the positioning of people, runways, aeroplanes and various other elements, which organizationally sustain a community of practice. Heath et al.'s (1999) work on London Underground train drivers similarly suggests that drivers do not only look at, for example, an approaching platform, but build accounts of scenes through regular, organizationally routinized means (also see Heath and Luff, 1999; Suchman, 1993). Even in situations when 'seeing' appears to rely entirely on visualization technologies such as laparoscopic video (Mondada, 2003), mammography (Hartswood et al., 2002), oceanographic sensors (Goodwin, 1995) or electron 
microscopy (Lynch, 1985), 'seeing' involves an orientation to organizational relations and realities. Determinations of what a phenomenon 'really is' are reflexively tied to the practical purpose of working out what to do next. This can, and sometimes does, involve questioning an image's relation to the phenomenon in question - an example is how scientists practically identify and manage artefacts in scientific evidence (Lynch, 1985).

This research into visual accounts builds on a broader ethnomethodological interest in the ongoing, accountable accomplishment of sense. For example, a turn-taking sequence in a conversation (such as a greeting and response), is accountably achieved by the participants in a conversation and becomes a part of how the participants accomplish a sense of the conversation (Garfinkel, 1967; Sacks, 1995). Visual account-ability in organizational settings might also be oriented toward such turn-taking activity. Precisely to allow for detailed study of turn taking and, more generally, 'the complex interdependence of actions' (Hindmarsh, 2009: 994), many studies on professional vision rely on digital video recordings of the social and interactional production of work. ${ }^{4}$

A second basis for understanding visual accountability is focused on how the visual is implicated in the distribution of relations of power and possibilities for action (Fyfe and Law, 1988). Many authors in this space have found it useful to draw on actor-network theory in order to conceptualize images as 'actors' (or actants) which, through their links with other human and nonhuman constituents of an assemblage, help facilitate and constrain accounts. ${ }^{5}$ In early actor-network descriptions of scientific knowledge production, 'inscriptions' such as graphs, tables, maps, photographs and other forms of documentary evidence, were allocated a key role in the transformation of empirical materials into credible and reliable knowledge (Latour, 1987, 1990). The notion that images and measurements - unlike, say, samples of organic materials - can be exchanged and combined without losing their integrity is captured in the term 'immutable mobile' (ibid.). So whereas ethnomethodological workplace studies view visual evidence in terms of the situated 'perception, monitoring and production of relevant action' that it occasions (Goodwin, 1995: 260), in early actor-network theory visual evidence obtains significance by virtue of its role within a 'cascade' of inscriptions that progressively, through the continual translation of things into signs, 'mobilize[s] larger and larger numbers of events in one spot' (Latour, 1990: 41; see also 1999). The most successful cascades are blackboxed as taken-for-granted understandings about, and organizations of, reality. It is in this way that images, as immutable mobiles, are implicated in the distribution of relations of power and possibility.

In more recent actor-network studies that focus, not on the cumulative construction of knowledge, but on the forms of relationality that pattern everyday organizational life, there is heightened attention to the multiplicity of visual accounts (eg Law, 1994, 1996; Mouritsen et al., 2001; Justesen and Mouritsen, 2009). Law (1996), for example, has shown how systems of managerial representation (ie how work is made visible) have a bearing on 
the kinds of agency that can be exercised by the people working in an organization (in this case, a research laboratory). A manager's discretion to intervene in a project that appears to be falling behind schedule is premised upon the technologies of accounting that make the delay visible. Subject and object, or 'seer and seen', are both constituted by the mode of accounting; and the mode of accounting is nothing else but the way in which objects and subjects are brought into specific and calculable relationships with one another. Organizational life, argues Law, routinely facilitates the movement of one mode of accounting into another - for example, from an administrative mode in which procedures and rules are key structuring devices, to an enterprise mode, in which managerial discretion becomes possible and desirable (Law, 1994). ${ }^{6}$

Everyday organizing depends on an array of (sometimes complementary, sometimes competing) mechanisms for 'pre-determining what is to count - and what, therefore, becomes counted' (Law, 1996:291) and visual images of various kinds can be pivotal to such arrangements. Justesen and Mouritsen (2009) show how multiple modes of accounting can be enacted through the same set of visual images, namely photographs and 3D visualizations in the annual reports of a property development firm, that serve both to engage the 'outside' world to the activities of the firm, and to enrol those affiliated with the firm in certain roles and obligations (see also Mouritsen et al., 2001). Law and Benschop (1997) juxtapose four traditions in painting (from geometrical Renaissance art to Aboriginal art) to show how these frame subject/object distinctions, narratives and spatialities in different ways. This juxtaposition serves to denaturalize a 'perspectival' mode of accounting in which everything has to add up, instead creating room for multiplicity. These developments of ideas from actor-network theory make it possible to situate visual images and their potential to be questioned beyond the well-known figure of the immutable mobile, which appears 'interrogable' only in the sense that someone might trace the reference back along the chain in an attempt to verify that representational forms preserve a trace of the materials they originated from. ${ }^{7}$

The distinct modalities of ethnomethodology (oriented toward moment-tomoment sense-making that displays the methods through which social order is done) and actor-network theory (focused on the organization and distribution of material effects and ontological difference) can help sensitize us to ways in which the use of visual evidence is rendered (un)stable in organizational interaction. However, the question if and how one might draw on ethnomethodology and actor-network theory simultaneously is not a trivial one, since they are frequently portrayed as incommensurable. ${ }^{8}$ Munro, in his work on numerical and verbal accounts, has shown a way in which the respective strengths of these distinct modalities can be deployed without rendering them commensurate. Munro argues that the presence of numerical artefacts has a bearing on the ongoing process of social ordering; a budget deficit, for example, presents a 'numerical gap' that demands an explanation. This demand, or 'hailing effect', remains unless and until explanations are offered that can help 
erase the gap (for example by attributing part of the deficit to foreign currency fluctuations, the key being that these can be expressed numerically). In this way the organized sets of relations with and around numbers can pre-empt the kinds of responses we offer. Often, if not always, such pre-empting is normative in nature; it is the very materiality of the artefacts which is "deciding" ahead which particular forms of accounts can be consumed' (Munro, 2001: 479, original emphasis). In the case of the deficit, narrative explanations that cannot be expressed numerically (the example Munro uses is looking after a spouse who is ill) are 'silenced' or prefigured as 'abnormal'. But responses to a call for accounts, for Munro (2004: 296), are also punctualized, which he describes as 'arriving on demand - and perhaps only for as long as the "call" lasts'. ${ }^{9}$ In our reading, hailing effects (with a focus on being called to account), prefiguring (with a focus on normativity) and punctualizing (with a focus on temporality), constitute ways in which people experience their ability to negotiate order as limited. Munro's work thus provides a basis for drawing together the idea of accountable ordering as constituted in and through networked relations (actornetwork theory) and the ongoing doing of accountable relations (ethnomethodology), without resolving their tensions.

In the remainder of this article, we pursue a similar aim, namely to draw ethnomethodology and actor-network theory into a productive tension, focused on asking how the visual - in the form of visual evidence - becomes concretely at stake in accomplishing accountability sensitive work. In considering surveillance images, photographs of traffic violations and mammograms, our focus is thus not on what these images mean (ie, the relation between image and referent), but on how they are mobilized and challenged as evidence; that is, if, when and how their quality, availability and ability to present useful information becomes accountably at stake. As part of our analysis, we will explore Munro's concepts of hailing effects, prefigured normality and punctualizing as possible features of interrogation and visual accountability.

\section{A. Accounting for a surveillance image}

The material for this first case was drawn together from extensive engagement with media sources (detailed below), collected over a four year period (20052009). Jean Charles de Menezes was shot seven times in the head by firearms officers as he sat on a London Underground train on 22 July 2005. He was mistaken for a terror suspect - Hussain Osman - whom police wished to talk to as a result of a series of failed bombings in London on 21 July 2005. When de Menezes entered the London Underground, police officers thought they were dealing with a potential suicide bomber, rather than an electrician who was late for work. Following the shooting, there were numerous calls for and attempts at accountability. First, there were two investigations carried out by the Independent Police Complaints Commission (IPCC) resulting in two reports - Stockwell 1 looking at the shooting itself and Stockwell 2 which investigated complaints from the de Menezes family about police officers' 
comments after the event. Second, the Metropolitan Police Authority, the watchdog for the Metropolitan police, passed a vote of confidence in the then Commissioner of the Metropolitan Police, Sir Ian Blair. Third, the London Assembly, an elected body connected to the mayor's office, passed a vote of no confidence in Sir Ian Blair following the incident. Fourth, there was a court trial based on the Health and Safety at Work Act (1979). These activities produced a significant number of issues regarding the nature of accountability (see Neyland, 2009). Of particular note for this article was the Health and Safety trial which focused on the visual evidence used by police officers to make their identification and inform their decision to shoot.

The first IPCC investigation (Stockwell 1) reported on the conduct of the Metropolitan Police Service. As a result of the IPCC investigation the Metropolitan Police Service were charged under the Health and Safety at Work Act with failing to protect the public from a potential terrorist. The IPCC report was presented as part of the evidence at the Health and Safety trial. Much of the trial depended upon reconstructing the events of the day of 22 July 2005 in order to render them available for accountability. This included drawing together logbooks from the control room at New Scotland Yard, CCTV images from street cameras and from public transport, and statements from police officers (commanders and surveillance officers) and public witnesses. Visual images became a particular focal point for these discussions. Questions were raised regarding the availability of visual images, how they were used and their provenance.

The courtroom itself, as a space of interrogation, generated a hailing effect: accounts (and people, things and relations that went into their production) were called forth into a hostile environment to be challenged. An episode in the court trial which exemplified this hostile questioning involved a visual image used by the police to demonstrate their difficulty in identifying or distinguishing Jean Charles de Menezes from Hussain Osman. The case was made by the defence QC for the police that the two individuals looked so similar, that the police - in mistaking de Menezes for Osman - had operated in much the same way as anybody else would have acted. The defence QC argued that de Menezes:

looked like the suspect and he had behaved suspiciously [by getting on and off a bus]. Not only did he not comply [with police requests], he moved in an aggressive and threatening manner as interpreted by the police and as would be interpreted by you and me in those circumstances, less than 24 hours after an attempt to bomb on the Underground and a bus had taken place. ${ }^{10}$

In order to emphasize this similarity between the two, a composite picture of de Menezes and Hussain Osman was designed by the defence to demonstrate the difficulties of identifying the suspect (Figure 1).

However, the prosecution claimed that the picture had been altered by 'either stretching or resizing, so the face ceases to have the correct proportions'. Michael George, a forensic expert called upon by the prosecution, 


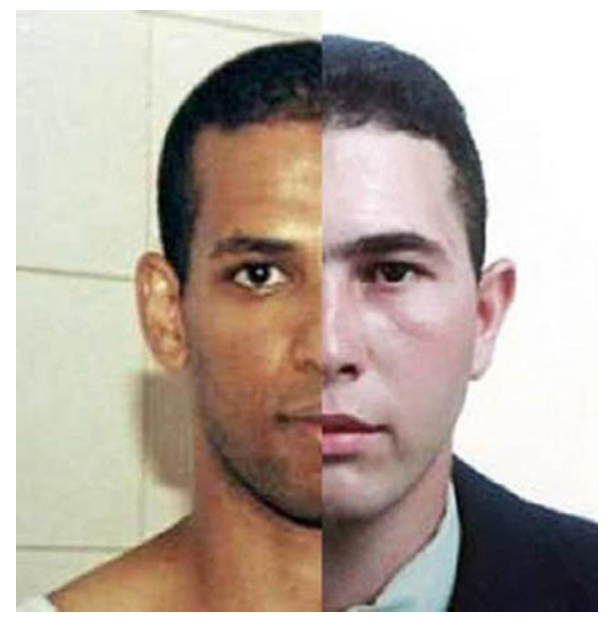

Figure 1 Defence composite image

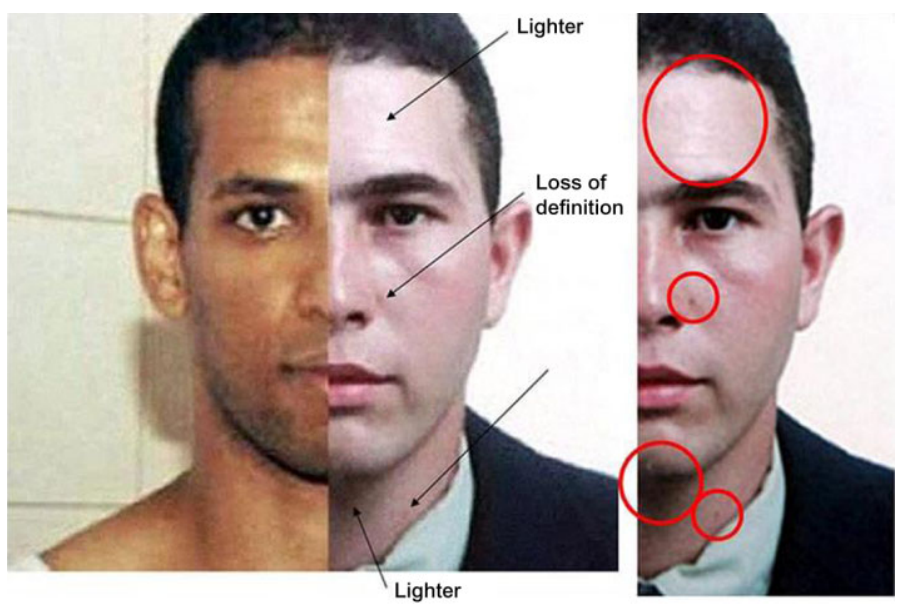

Figure 2 Questioning the composite image

reported that he had tried to recreate the picture using Microsoft PowerPoint, but could not. De Menezes' face, the prosecution claimed, appeared to have been brightened and had lost definition compared with the original police photo - particularly around the left nostril and chin (Figure 2). The defence countered that the attempt to show manipulation - particularly through the use of PowerPoint - was a 'pseudo-scientific exercise'.

The point here is not to prove either way the provenance of the image, but to illuminate the ways in which the debate about visual evidence in this court case highlights the complexity of the accountability process. Although 
attempts were made to present the visual image as evidence that the police acted appropriately, that they were certain in their (mistaken) identification and did as much as any police officers could do, the visual image did not retain the capacity to evince this certainty. Arguments in the court were characterized by a switching between the certainty and uncertainty of the visual identification. The composite picture was used in an attempt to demonstrate how much de Menezes and Osman looked alike, yet it ended up generating questions about its provenance and about the integrity of the Metropolitan Police.

The dynamics through which visual evidence is given credence, and is undermined, in legal contexts have been analysed by Goodwin (1994), Jasanoff (1998), Cole (1998), and Lynch and McNally (2005), among others. Apart from the legal tactic of linking the credibility of the evidence to the integrity of all parties involved in its production, these authors have also drawn attention to disputes about visual authority. These are perhaps most sharply brought into view around photo-realistic images that seem to show what is the case plainly and beyond doubt. Both Goodwin (1994) and Jasanoff (1998) discuss attempts (by the opposing counsel) to undermine the tendency to take videotape evidence at face value, by arguing that what the images appear to show may not be what they actually show, and that only an expert is able to 'code' such evidence correctly.

In the Health and Safety trial discussed here, legal argument took the form of questioning whether the composite image could be taken to plainly show anything at all. Drawing inspiration also from Livingston's (2006) work on proving, we can analyse the use of the composite image that was presented as a demonstrative proof (of the difficulties involved in making identification) as merely one move in a series of turns of questioning. The proof was presented, in hand, obviously and recognizably as it was. Its accountable order, the provenance of its production, was at this moment not made prominent. ${ }^{11}$ However, the trial was a moment of interrogation - that is, the prosecution asked questions of this missing provenance. They wanted to know how the proof was reached. Although the image may have appeared to be obviously and recognizably what it was, under the intense interrogation of cross-examination the composite image was challenged as a distortion. The fact that the image could not be recreated using a simple tool like PowerPoint was heralded now as the proof of this ill-gotten provenance. PowerPoint was called upon by the prosecution to reveal the image as obviously and recognizably what it now was (a fake), by making the audience aware of obviously what it was not (a genuine juxtaposition of two original photographs).

This turn in the sequence of interrogation involved articulating the new image (Figure 2) as more genuine and original than the defence image (Figure 1) ever was - in line with the claim made during the trial that the composite image presented by the defence was a distortion. Turn taking and timing the moment of revelation were important here not just for establishing the nature of the images (as originals or distortions) but also for establishing 
a new accountable order; responsibility was to be attributed for the ill-gotten provenance of the distorted image. But the interrogation continued as the defence responded with a further turn, charging that the prosecution were using a pseudo-scientific exercise, involving PowerPoint, to ask questions of the image. This turn signalled a move towards interrogating provenance without presenting new, alternative images. Whose provenance were you going to believe - the police's or PowerPoint's? ${ }^{12}$

In the Health and Safety trial, the distribution of accountability relations both affected, and was affected by, the opening up of the composite image to intense interrogation. ${ }^{13}$ What may have been designed as a (more or less) straightforward piece of organizing and distributing accountability relations around a visual image (who should have acted in what way and to whom, and who did act in what way and to whom), became more problematic once the focus and intensity of interrogation switched to the nature, history and content (which in turn account for the reliability) of the image itself. The interrogation of visual provenance became a means by which accountable orders of the image, the defence case and the Metropolitan Police were pursued. The interrogation of the accountable order of the image (the work done to make it obviously, recognizably, justifiably the way it was) and questions of accountability (who or what should take responsibility for the ordering work and with what consequences) were intricately linked.

This first case has drawn attention to the opening up, by way of detailed interrogation, of an image's provenance and the ordered sets of relations deemed normal and appropriate for deciding its accountability (Munro, 2001, 2005). In order to explore an alternative temporal dimension, maintained through the closing down of interrogation and stabilization of accountability relations and visual evidence, we will now turn attention to our second example, drawing on research into speed cameras.

\section{B. Accounting for drivers' actions through images}

The research for this case was funded by the ESRC under the Science in Society programme and involved qualitative research (ethnography and interviews) in 10 safety camera Partnerships around the UK over a period of two and a half years. In 2000, in response to mounting criticism regarding the possibility that speed cameras were unregulated and primarily designed to raise revenue, the UK government (Department for Transport, Home Office and the Treasury, with PA Consulting) introduced a pilot system for the formation of regional Safety Camera Partnerships. Linked to a national Safety Camera Board, these Partnerships would be given responsibility for installing and managing speed cameras across Britain. Partnerships could include local police, highways agencies, unitary authorities and other local political groups, NHS trusts, Partnership managers, road safety engineers and communication staff. The eight pilot Partnerships were expanded over 5 years to 38, encompassing 4,500 fixed speed cameras and 1,000 mobile cameras. 
Until 2007-8, national guidelines established that each year the Partnerships were to present their 'operational case' and 'communications case' to the Board for assessment. The Partnerships were enabled to generate income from the scheme only after the Board had established that the cases adhered to the guidelines. The operational case should make clear the number of cameras to be installed in the forthcoming year, the justifications for the sites at which these cameras were going to be installed, the costs of putting in new and maintaining existing sites and the overall costs and projected income for the Partnership. Partnerships were thus to be held to account by national government (Department for Transport) for the extent to which they adhered to the Guidelines in making cases regarding spending, number of cameras, position of cameras and so on. Partnerships, in turn, would hold drivers to account for their driving. Visual evidence, the photographs of drivers going too fast past speed cameras, was crucially important for accomplishing accountability.

'Income' for Partnerships equated to the predicted level of speeding offences which would be committed and paid in the forthcoming 12 months. The guidelines were clear that such a figure should take into account previous years' figures, expectations that cameras would slow people down, the possibility that some fines would never be paid and the possibility that some drivers would go to court. The latter was particularly problematic for Partnerships as the guidelines established that drivers who disputed their speeding penalty by going to court would, upon conviction, pay the court while the Partnership would receive none of the penalty income. ${ }^{14}$

It was thus in the Partnerships' interest to get drivers to pay without dispute, and they spoke of their level of success in doing so as the 'flash to cash' rate. Paradoxically, although the Partnerships were involved in holding drivers to account for their actions and this accountability was visually oriented, it was a central feature of Partnership activities that drivers did not (or only on a limited basis) seek to review and dispute the photographs taken by speed cameras. Many of the 38 Partnerships would only send drivers an image of their 'speeding' on request, drivers would be encouraged to pay quickly through instructions that otherwise penalties would increase (to court cases, criminal records, bailiffs taking and selling possessions to cover penalty costs), and drivers would be given all the instructions required to make a swift payment in person or over the phone. All these measures were designed to close down opportunities for drivers to interrogate the visual evidence.

Partnerships talked about a variety of issues involved in getting drivers to pay. First there was a problem with drivers using excessive speed which would lead to a court case and no Partnership revenue. Second, there were drivers who did not pay quickly for a variety of reasons. Partnerships made decisions on the extent to which they would pursue drivers in their area who had not paid. Sometimes this related to the number of penalties they had to administer, whether or not they had the administrative capacity or need to chase non-payment. Third, some Partnerships felt they were in a game with drivers 
who they thought were being encouraged to dispute penalties by campaigning websites and books or guidelines being published on how to avoid paying for a penalty. The Association of British Drivers and Motorists against Detection were seen as notable examples of this anti-penalty/anti-camera campaigning.

Organizing this visual form of accountability, ensuring that on the whole the absent visual evidence was accepted and payments forthcoming, required some delicate work. Access to images of speeding was withheld until requested by drivers. However, Notices of Intended Prosecution sent to drivers made it clear that such visual evidence was available, using phrases such as:

This allegation WILL be supported by photographic evidence at any subsequent court hearing.

The penalty notices issued by Partnerships devoted much space to methods of payment, ease of payment and punishment for non-payment, while the option to appeal was marginalized to an obscure section of the notice. ${ }^{15}$

A general feature of this example of visual accountability is the asymmetrical 'mode of accounting' (Law, 1996) through which relationships between drivers and Partnerships were structured. It was the Partnerships who decided what the image represented and what action should follow, who should be held to account and the correct process of accountability, while ensuring drivers had fewer opportunities to hold Partnerships to account in relation to particular penalties. ${ }^{16}$ Drawing on Munro's $(2004,2005)$ work, we can consider the Notices of Intended Prosecutions as materially instantiated organizations of accountability relations that permit Partnerships to hold drivers to account while simultaneously closing down opportunities for drivers to interrogate Partnerships or specific items of visual evidence. The Notices were designed as a means to punctualize accountability relations - arriving within a specific timeframe, demanding a timely response and pre-figuring the options to respond (Munro, 2004). In this sense, drivers were called upon to recognize that they were being held to account, should take on responsibility for their actions and should pay their penalty within the time limit. Furthermore, the images were not released first, the penalties were made to look threatening and payment was presented as the easiest response. Through such means, drivers were 'configured' (Woolgar, 1991) to inhabit their roles as those who were speeding, those who had been caught and those who were the owners of a speeding car. Trouble occurred for Partnerships when drivers resisted their configuration and started to question the provenance of the image (by asking to see it) and, subsequently, the integrity of the organization producing the image. It was at these moments that Partnerships lost some of their income.

This mode of visually organized accountability was focused on the visual image not being interrogated, its provenance not being challenged. In place of a historical trajectory, questions of accountability were held very much in the present as drivers were offered a brief opportunity in which to recognize the existence of visual evidence, their position in accountability relations and their 
appropriate response (to pay) before punishment would escalate. It appeared that it was especially important that questions regarding the provenance of the image were ruled out, because expectations regarding the image's existence and nature - that is, that the Partnerships were in possession of a photograph, and that this was a photograph that definitively showed evidence of this car/driver speeding - were implicated in the way accountability was distributed and took shape. The penalty notices presented an account of speeding as being obviously, recognizably and justifiably the way it was, with the image held by the Partnership and referenced (but not presented) in the letter as evidence of this indisputability. Unlike the first example, visual provenance was not in question as long as the focus was on getting on with the everyday business of managing speed cameras and paying fines. The image could be held at the centre of the arranged accountability relationships precisely by virtue of exempting it from interrogation. The taken-for-grantedness of the visual evidence and relatively low number of requests for images was an indicator of the 'strength' - in actor-network terms - and 'punctualized hailing effects' - in Munro's terms - of these arrangements. ${ }^{17}$

Alongside the detailed interrogation of the provenance of visual images in the first case and attempts to restrict interrogation in the second case, relations of visual accountability can also be organized around projections of likely future actions. This third temporal dimension will be addressed in the next section through the example of mammography.

\section{Accounting for the future through mammography}

The material for our final case was collected as part of an ethnographic study on the commercialization of new software for medical imaging over 12 months in 2002-2003 (Coopmans, 2006). ${ }^{18}$ In 2002, what was then the UK's Department of Trade and Industry ${ }^{19}$ approved a funding proposal for a two-year research project to invigorate the use of a relatively old type of medical imaging - mammography - with new technologies. The technologies in question were the 'Grid', a distributed computing infrastructure through which computing power and data repositories could be shared; and computer vision algorithms through which information could be automatically extracted from digital medical images. The project, which was partly funded by the private sector, involved collaboration between academics, commercial technology developers and clinical representatives associated with four hospitals in different parts of the country. The aspiration of this multidisciplinary project team was to provide 'an exemplar of the dynamic, best-evidence based approach to diagnosis and treatment made possible through the Grid', (quoted from the funding proposal). The basis for achieving this 'dynamic, best-evidence based approach' was the transformation of existing mammograms into data objects stored in a database in digital and standardized form.

This new (prospective) existence of mammograms as digital, networked objects opened up the possibilities for reconsidering their very nature as 


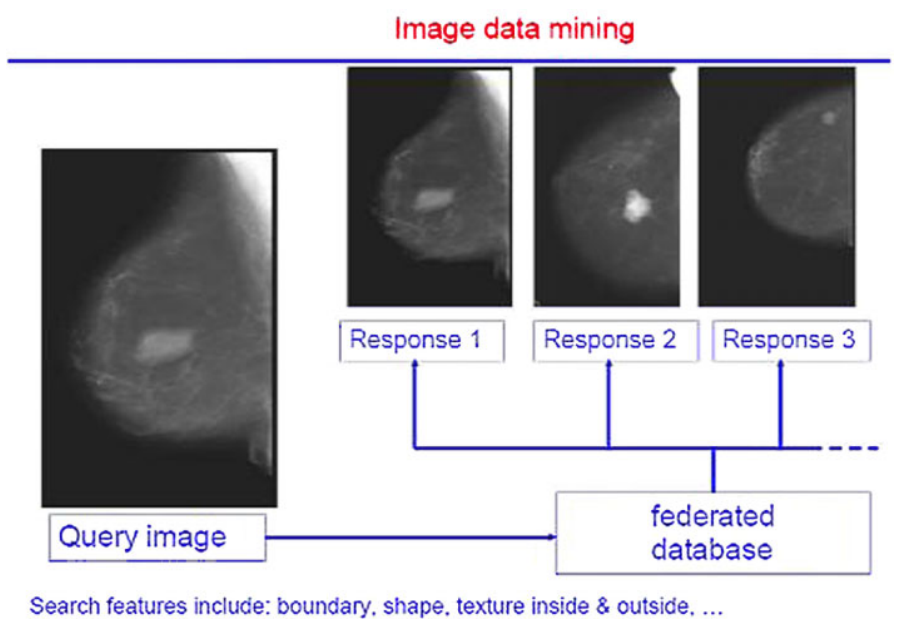

Figure 3 Automatic visual comparison of mammograms. Image used with permission from Ralph Highnam and Michael Brady

evidence of early-stage cancer. For example, one proposed application sought to deploy automatic comparisons across a large database of images to help interpreters decide on features that could not be readily classed as 'clearly benign' or 'clearly malignant'. Cancerous and non-cancerous physiology can look very similar on a mammogram, while variations in the technical production of the images can lead to further confounding effects. Studies measuring diagnostic consistency had drawn attention to the fact that even experienced radiologists can come to different conclusions about the same set of mammograms, and also to the significant number of cases where carcinomas were seen retrospectively on mammograms originally interpreted as 'normal'. The idea was that future diagnostic practice might use Grid infrastructure and computer vision algorithms to establish shared visual features between new (still to be interpreted) mammograms and a body of evidence from previously diagnosed cases (Figure 3). Over time, a large database of cases would build up, enabling increasingly refined and reliable comparison:

[I]f the radiologist is not sure whether the object being studied is benign or malignant, she will search the database for similar cases [with this software]. The database will return the nearest 10 (say) matches and the radiologist can either look at the distribution of those matches ('all benign, so this must be benign', or '70\% malignant so this is worth looking at closer') or look at individual cases and compare. (Minutes of the Project's Start Up Meeting, 14 November 2002).

Amongst members of the project team, this idea of automatic comparison was discussed in light of how mammograms currently functioned in 
radiologists' diagnostic practices and how they might function in the future. In these discussions, the interrogability of present and future (digital, networked) mammograms became the focal point for an articulation of accountability relations. The researchers who had fielded the idea sought to deploy computational power where human eyes fell short. However, two radiologists who acted as consultants for the project argued that they lacked the time to scrutinize computer-generated comparative cases. They also questioned the need for it. Did these radiologists not want to improve the accuracy of their interpretations?

The radiologists explained to members of the project team that the mammographic image was only one of multiple components that helped them make accountable decisions. When faced with an image whose features appeared to fall in the grey zone between 'clearly benign' and 'clearly malignant', radiologists deferred the diagnostic decision to another, non-visual, test: the biopsy. Rather than trying to 'see' the absence or presence of cancer on a set of mammograms, radiologists oriented their work to deciding whether, based on the visual evidence presented, further tests should be undertaken. This decision making was not about removing ambiguity, but managing it; the tests were an accountable feature of ambiguity management.

Ethnomethodological studies of mammogram interpretation conducted in the mid and late 1990s (eg Hartswood et al., 2002) also featured in these discussions about the role of the image in diagnostic practice. These studies portrayed the work of radiology as the rapid assembling of a context within which a particular decision could be established as valid and reasonable. Details of a woman's medical history, radiographers' notes on the technical details of image acquisition, previous images, additional angles and views, hands, rulers, magnifying glasses, bright lights and opaque films could all be made a part of rendering the features on a mammogram visible as what they accountably were. Sometimes, suspicious appearances could be dismissed (that is, treated as not actually suspicious), based on what the radiologist understood about the context of image production and about the diversity of tissue compositions and mammographic appearances associated with healthy breasts. Via the training of novices and the routine use of second opinions for screening mammograms, a socialized sense of professional vision emerged in the screening organization.

The radiologists' comments and the results from the ethnomethodological studies sought to establish that, in ordinary screening practice, the features on a mammogram were closely interrogated, but not with the aim to draw a fine line between 'benign' and 'malignant'. The irresolvable ambiguities associated with the grey zone were not a problem for the accountable work of breast screening. The image's status as visual evidence was relatively secure as long as the radiologist could establish that its features were obviously, justifiably and recognizably not in the grey zone. However, if an ambiguous feature could not be explained away swiftly and confidently through situated reasoning then further tests were necessary, the diagnostic decision was deferred and the image no longer served as prime evidence. 
The prospect of automatic comparison, on the other hand, pre-figured accountability relations differently by turning the ambiguity associated with the grey zone into something that had to be resolved rather than managed. Resolving ambiguity depended on a new way of interrogating mammograms, one that was premised on algorithmic ways of characterizing image features and on a growing database of cases to find correlation between visual appearance and diagnostic truth. In actor-network terms, while in existing practice mammograms were not treated as immutable mobiles (that is, their manifestation as evidence was not singular and stable), the new system began to resemble a cascade of inscriptions in and through which the status of each mammogram could gradually be fixed. ${ }^{20}$ In contrast to existing practice, in which a radiologist's interrogation of the image was lodged within the shared and account-able professional vision of the breast screening unit, the tool's interrogation of the image was aimed at dissolving the grey zone into quantitatively defined linkages between (perhaps barely perceptible) visual features and their likelihood of representing early stage cancer.

As a result, whereas in existing screening practice, deferral was a workable and accountable way of dealing with ambiguities, in future radiologists might be held to account for resolving these ambiguities at the level of the image itself. In a temporal sense this would also punctualize accountability, by 'demanding' the delivery of a diagnostic decision in the here-and-now (cf. Munro, 2004). These prospective manifestations of visual evidence, organizational action and relations of accountability were articulated by the radiologist-consultants as a matter of concern. Implementation of the prospective tool and its imagined accountability relations might introduce hailing effects such that radiologists would have to account for why they accepted or rejected its results. The tool's interrogation of the image would thus become part of the radiologist's interrogation, but without providing the radiologist with an account (about the grounds for its selection of some images as similar and others as different) that was congruent with the radiologist's own. Radiologists, in other words, did not have the resources to accountably challenge or ratify - the results provided by the automatic comparison tool, and this made the two radiologist-consultants for the project hesitant about the idea. We are grateful to one of the anonymous reviewers of an earlier version of this paper for helping us develop this last point.

In the discussion about the prospects for automatic comparison in breast screening, different understandings and preferences for the interrogability of mammograms came to the fore together with their possible future consequences for radiologists' accountabilities. Although the logic of an algorithmic approach premised on the isolation of disease-relevant features and their linkages to epidemiologically established probabilities appears to fit with calls for evidencebased medicine, the repositioning it entailed, of mammograms as a form of visual evidence, highlighted tensions in the accountable organization of breast screening work. The tool was seen to challenge the visual accountability that governed current breast screening practice, by redefining the way in 
which disease features were recognized, on mammograms, as what they obviously, recognizably and justifiably were. In response to this prospective challenge, radiologists in turn challenged the visual accountability projected by the tool.

\section{Conclusion}

We can now try to be more precise about the advantages of establishing 'interrogation' as a basis for examining the relationship between accountability and the visual. First, we can treat acts of interrogation as moments in which accountabilities are being settled and discharged, but also as a focus for recognizing the possible disturbance of accountability relations. In this sense, the composite image in the Jean Charles de Menezes case is initially presented as providing such an obvious and clear distribution of accountabilities (the police acted in the way they did because these two individuals looked so similar, as you can see in this image), that no interrogation (for example, regarding the provenance of the image) appears necessary. The image is presented as speaking for itself and thus being account-able. We can see a similar capacity attributed to images in the other two cases, with speeding images held by Partnerships and referenced in penalty notices, and mammograms speaking for the absence or presence of disease as long as their features are not within the grey zone between clearly benign and clearly malignant. The effectiveness and persuasiveness of visual images as evidence is premised upon a certain distribution of accountabilities. At the same time, it is possible for participants to interrogate visual evidence in such a way that this distribution is unsettled or becomes disturbed (how was the composite image produced, can I see the image of me speeding, how should ambiguous features be made sense of?). It is from this 'opening up' that further forms of interrogation follow (did the police act as initially suggested, is it me speeding, should radiologists diagnose or defer?) and further questions of accountability are inspired (how ought the police be held to account as a result of this interrogation, should I now go to court to dispute this speed camera image, should radiologists be held to account for use or non-use of computer-generated analyses of networked mammograms?). In principle, this process of accountability disturbance, through interrogation, leading to further interrogation of accountability, has no end.

Second, the examples presented highlight the prevalence of activities to close down interrogation of visual evidence, especially where it threatens to disturb accountability relations. Thus, although in principle forms of interrogation leading to a questioning of accountability relations have no end, in practice various actions are carried out to pre-figure and hence punctualize these questions. The Safety Camera Partnerships imply but do not present drivers with visual evidence; the radiologists call patients in for further tests rather than rely on visual images; and the police defence in the Jean Charles de Menezes case does not involve a direct rebuttal of prosecution claims, but 
rather an attempt to redirect the form of interrogation (by questioning the use of PowerPoint). It is through these practices that interrogability is limited.

Third, what we find across the three examples are temporal dimensions of accountability made apparent through acts of interrogation. Others have pointed to the way in which the past and the anticipated future form reference points for the interpretation and use of visual evidence in science (Lynch, 1985; Woolgar, 1990). In our analysis, we place less emphasis on how pasts and futures are drawn upon as resources for image interpretation - and more emphasis on how images become focal points for projecting the basis for organizational action back to the past, onto the present and into the future. Hence in the first example questions are asked of provenance, lending the interrogation a historical trajectory. In the second example, work is done to hold a focus on the present; it is the driver who is held accountable and who needs to respond by paying the fine (rather than open up for dispute the visual evidence and the accountability relations through which both the evidence and the fee-paying mechanisms are constituted). And in the third example, the future-oriented development of new analytical tools that change the way mammograms are treated as visual evidence, entails a reconfiguring of accountability relations for radiologists. Hence temporal dimensions appear to form an important basis for the organization and distribution of accountability.

In sum, we have proposed three focal points as contributions to the literature which analyses entanglements of the visual and the accountable. These follow from the use of 'interrogation' as a conceptual tool for developing an understanding of the ways accountability relations are enacted through visual evidence in diverse cases and circumstances. The three points are: the opening up of images to dispute (asking questions of for whom, of what and in which way the images speak); the closing down of possibilities for questioning images and the organizational actions with which they are articulated (via custodianship of images conferring opportunities to accomplish beneficial distributions of accountability relations such that custodians get to hold to account without being held to account); and a focus on temporal dimensions of accountability (in the sense that each mode of accomplishing visual accountability is oriented to a particular temporal horizon). One important feature of these focal points is the anticipation that visual evidence will move between stable and unstable states in the process of being articulated with accountability relations. Visual evidence-inuse signals its in-principle interrogability even if it is not at present subject to interrogation, and when it is subject to interrogation it signals that its integrity might be (re-)settled..$^{21}$ By developing this general insight, the three focal points of opening up, closing down and temporality suggest a rich seam of potential future interrogation of the role of various sorts of visual evidence in accountability relations, which could be productively explored by further studies. 


\section{Notes}

1 Although this is a currently fashionable way of talking about accountability (Neyland, 2006), such discussions over the 'recent' rise of accountability are traceable across at least 40 years of social science research (see, eg, Williams, 1973). Pertinent analyses of demands for and techniques of accountability in the past twenty years include Power $(1994 ; 1995 ; 1997)$ and Strathern (1999a, 2000b, 2002).

2 Most social science interest in interrogation is focused on police work and, in particular, the work of police officers (see, eg, Leo, 1996; Irving and Hilgendorf, 1980). In this context, interrogation has a specific history, elaborate techniques, dedicated technologies and occasionally recognized experts.

3 Although these authors focus on the work of accounting and accountability, their theoretical starting points are distinct. The work of Power draws on neo-Foucauldian notions to explain audit rationales, whereas Munro and Strathern focus more closely on material practices in the organization of accountability. Munro (2005) offers an analysis of Strathern's (1999b) work as one basis for developing his argument that in order to see and account for some matter, one needs to be in a position to see what is to be seen.

4 As such, they not only show how the visual plays a role in the building of accounts, but also exhibit visual accountability in sociological method.

5 This line of argument, relating visual accountability to notions of power and possibility, also draws on and builds on the work of Foucault on surveillance and the gaze (Foucault, 1977, 1980). However, to the extent that the gaze is often seen as a one-sided instrument of control, actor-network theory appears to provide an approach whereby the role of the visual can be equally powerful but is less settled.

6 See also Munro (1996) for an analysis of centres of calculation and centres of discretion.

7 This of course is what makes (scientific) knowledge accountable and is used in Latour's early work as an explanation for the strength of knowledge claims. See Lynch and McNally (2005) for an account of the work involved in preserving continuity in the case of legal 'chains of custody'.

8 Indeed, criticism from authors allied to each approach has sometimes been pointed. See, for example, Latour (1986) and Lynch (1996).

9 Building on Heidegger and also Derrida's critique of Heidegger, punctualizing is used by Munro for working through the complexities of identity; in particular to provide an alternative to social theories that emphasize the fluidity of identity. Our use of punctualizing takes from this discussion the point that timing is important in how arrangements - including those that entail visual accountability - are made to reveal themselves. The idea that a 'demanding relation brings into the instant - the Now! - what otherwise might be deferred, or left distant' (Munro 2004: 309) provides a clue as to why and how visual evidence is made compelling in particular situations. See in particular the case of traffic violations below.

10 This and the following quotes are based on a newspaper report in the Guardian, 18 October 2007, p. 4.

11 Unlike the composite images studied by Daston and Galison (1992) this image was presented without any particular articulation of provenance, leaving it up to those in the courtroom to pose particular questions of where the image had come from, by whom it was produced, for what purpose and so on.

12 Such a scene, according to Latour (2008), is not unusual in moments of demonstration where a phenomenon hardens into a genuine fact or quickly dissipates as an artefact; the demonstration shifts between being noted as apodeixis (rigorous demonstration) and epideixis (rhetoric) whereby such a designation is an accomplishment or outcome rather than an a priori certainty.

13 The accountabilities in this case were multiple. The police surveillance team were to be held to account for their problems in producing an identification of de Menezes. Senior commanding officers were accountable for failing to adequately communicate their certainty/uncertainty of identification. Firearms officers, it was suggested during the trial, should be held to account for 
arriving late at the scene. The integrity of the Metropolitan Police as an aggregate entity came under questioning during the trial.

14 This arrangement was based on a Home Office hypothecation system.

15 This is in line with UK traffic management processes generally where the term 'appeal' has all but been removed from enforcement. For example, many UK parking tickets, now termed Fixed Penalty Notices, make no mention of 'appeal'. Instead the Notices contain a long and difficult to type e-mail address to which drivers may send an 'enquiry'.

16 There are other ways in which Partnerships are held to account. Under the Freedom of Information Act, Partnerships are called upon to make information available on websites and on request regarding the positioning of cameras and casualty reduction rates for the last few years of Partnership operation. They do not have to tell drivers when cameras do and do not contain film.

17 Another example of an arrangement in which the suggestion that visual evidence is 'available' serves to organize accountability relations without sparking attempts to interrogate the evidence, is provided by Mulla (2011) in her discussion of legal uses of photographs of victims of sexual assault. Here the quantity of visual evidence made the difference. Mulla quotes a nurse examiner: 'They did not even look through the pictures [...], they just caved as soon as they saw how much there was.'

18 This research was financially supported through a PhD scholarship at Saïd Business School, University of Oxford. From 2004 to 2008, themes were developed at the Innovation Studies Centre at Imperial College Business School, London; financial support from the EPSRC Innovative Manufacturing Research Centre programme during that period is gratefully acknowledged.

19 Now succeeded by the Department for Business, Innovation \& Skills.

20 For a complementary discussion of how'database logic' affects ways of working with medical images as diagnostic evidence, see de Rijcke and Beaulieu (2014).

21 In this respect, the image that is the focus of such interrogability is akin to Hetherington and Lee's 'blank figures', which 'are underdetermined and motile within a specific set of conditions of possibility whose effects are uncertain and not entirely predictable' (2000: 177, emphasis in original).

\section{References}

Callon, M. and Law, J., (2005), 'On qualculation, agency, and otherness', Environment and Planning D: Society and Space, 23: 717-733.

Cole, S., (1998), 'Witnessing identification: latent fingerprinting evidence and expert knowledge', Social Studies of Science, 28 (5-6): 687-712.

Cooper, R., (1993), 'Technologies of representation', in Pertti Ahonen (ed.), Tracing the Semiotic Boundaries of Politics, 279-311, Berlin: Mouton de Gruyter.

Coopmans, C., (2006), 'An ethnographic study of medical imaging: mobility, representation, boundaries and utility in a digital age', DPhil thesis, University of Oxford, UK.

de Rijcke, S. and Beaulieu, A., (2014), 'Networked neuroscience: brain scans and visual knowing at the intersection of atlases and databases', in Catelijne Coopmans, Janet Vertesi, Michael Lynch and Steve Woolgar (eds), Representation in Scientific Practice Revisited,131-152, Cambridge, MA: MIT Press.

Daston, L. and Galison, P., (1992), 'The image of objectivity', Representations, 40: 81-128.

Foucault, M., (1977), Discipline and Punish, London: Allen Lane.

Foucault, M., (1980), 'The eye of power', in Colin Gordon (ed.), Power/Knowledge: Selected Interviews and Other Writings 1972-1977, 146-165, New York: Pantheon Books.

Fyfe, G. and Law, J. (eds), (1988), Picturing Power: Visual Depiction and Social Relations, London: Routledge.

Garfinkel, H., (1967), Studies in Ethnomethodology, Englewood Cliffs, NJ: Prentice-Hall. 
Goodwin, C., (1994), 'Professional vision', American Anthropologist, 96 (3): 606-633.

Goodwin, C., (1995), 'Seeing in depth', Social Studies of Science, 25 (2): 237-274.

Goodwin, C. and Goodwin, M.H., (1996), 'Seeing as situated activity: formulating planes', in Yrjö Engeström and David Middleton (eds), Cognition and Communication at Work, 61-95, Cambridge: Cambridge University Press.

Hartswood, M., Procter, R., Rouncefield, M. and Slack, R., (2002), 'Performance management in breast screening: a case study of professional vision and ecologies of practice', Journal of Cognition, Technology and Work, 4 (2): 91-102.

Heath, C., Hindmarsh, J. and Luff, P., (1999), 'Interaction in isolation: the dislocated world of the London Underground train driver', Sociology, 33 (3): 555-575.

Heath, C. and Luff, P., (1999), 'Surveying the scene: the monitoring practices of staff in control rooms', in Jan Noyes and Martin Barnsby (eds), Proceedings of People in Control: An International Conference on Human Interfaces in Control Rooms, Cockpits and Command Centres, 1-6, University of Bath: IEE Press.

Hetherington, K. and Lee, N., (2000), 'Social order and the blank figure', Environment and Planning D: Society and Space, 18: 169-184.

Hindmarsh, J., (2009), 'Work and the moving image: past, present and future', Sociology, 43 (5): 990-996.

Irving, B. and Hilgendorf, L., (1980), Police Interrogation: The Psychological Approach (Royal Commission on Criminal Procedure Research Study No. 1), London: HMSO.

Jasanoff, S., (1998), 'The eye of everyman: witnessing DNA in the Simpson trial', Social Studies of Science, 28 (5-6): 713-740.

Justesen, L. and Mouritsen, J., (2009), 'The triple visual: translations between photographs, 3-D visualizations and calculations', Accounting, Auditing \& Accountability Journal, 22 (6): 973-990.

Latour, B., (1986), 'Will the last person to leave the social studies of science please turn on the tape-recorder?' Social Studies of Science, 16: 541-548.

Latour, B., (1987), Science in Action: How to Follow Scientists and Engineers through Society, Milton Keynes: Open University Press.

Latour, B., (1990), 'Drawing things together', in Michael Lynch and Steve Woolgar (eds), Representation in Scientific Practice, 19-68, Cambridge, MA: MIT Press.

Latour, B., (1999), 'Circulating reference: sampling the soil in the Amazon forest', in Pandora's Hope: Essays on the Reality of Science Studies, 24-79, Cambridge, MA: Harvard University Press.

Latour, B., (2008), 'The Netz-Works of Greek deductions', Social Studies of Science, 38 (3): 441-459.

Law, J., (1994), Organizing Modernity, Oxford: Blackwell.

Law, J., (1996), 'Organizing accountabilities: ontology and the mode of accounting', in Rolland Munro and Jan Mouritsen (eds), Accountability: Power, Ethos and Technologies of Managing, 283-306, London: International Thomson Business Press.

Law, J. and Benschop, R., (1997), 'Resisting pictures: representation, distribution and ontological politics', in Kevin Hetherington and Rolland Munro (eds), Ideas of Difference: Social Spaces and the Labour of Division, 158-182, Oxford: Blackwell.

Leo, R., (1996), 'Inside the interrogation room', Journal of Criminal Law and Criminology, 86: 266-303.

Livingston, E., (2006), 'The context of proving', Social Studies of Science, 36 (1): 39-68.

Lynch, M., (1985), Art and Artifact in Laboratory Science: A Study of Shop Work and Shop Talk in a Research Laboratory, London: Routledge \& Kegan Paul.

Lynch, M., (1996), 'DeKanting agency: comments on Bruno Latour's "On interobjectivity", Mind, Culture, and Activity, 3 (4): 246-251.

Lynch, M. and McNally, R., (2005), 'Chains of custody: visualization, representation and accountability in the processing of forensic DNA evidence', Communication and Cognition, 38: 297 318. 
Mondada, L., (2003), 'Working with video: how surgeons produce video records of their actions', Visual Studies, 18: 58-73.

Mouritsen, J., Larsen, H. and Bukh, P.N.D., (2001), 'Intellectual capital and the "capable firm": narrating, visualising and numbering for managing knowledge', Accounting, Organizations and Society, 26 (7-8): 735-762.

Mulla, S., (2011), 'Facing victims: forensics, visual technologies, and sexual assault examination', Medical Anthropology, 30 (3): 271-294.

Munro, R., (1996), 'Alignment and identity work: the study of accounts and accountability', in Rolland Munro and Jan Mouritsen (eds), Accountability: Power, Ethos and the Technologies of Managing, 1-19, London: International Thomson Business Press.

Munro, R., (2001), 'Calling for accounts: numbers, monsters and membership', Sociological Review, 49 (4): 473-494.

Munro, R.,(2004), 'Punctualizing identity: time and the demanding relation',Sociology, 38:293-311.

Munro, R., (2005), 'Partial organization: Marilyn Strathern and the elicitation of relations', Sociological Review, 53: 245-266.

Neyland, D., (2006), Privacy, Surveillance and Public Trust, London: Palgrave Macmillan.

Neyland, D., (2007), 'Achieving transparency: the visible, invisible and divisible in academic accountability networks', Organization, 14 (4): 499-516.

Neyland, D., (2009), 'Surveillance, accountability and organisational failure: the story of Jean Charles de Menezes', in Benjamin Goold and Daniel Neyland (eds), New Directions in Surveillance and Privacy, 107-32, Cullompton: Willan.

Neyland, D. and Woolgar, S., (2002), 'Accountability in action: the case of a database purchasing decision', British Journal of Sociology, 53 (2): 259-274.

Power, M., (1994), The Audit Explosion, London: DEMOS.

Power, M., (1995), Audit and the Decline of Inspection, London: CIPFA, Public Finance Foundation.

Power, M., (1997), The Audit Society, Oxford: Oxford University Press.

Quattrone, P. and Hopper, T., (2006), 'What is IT? SAP, accounting, and visibility in a multinational organisation', Information and Organization, 16 (3): 212-250.

Sacks, H., (1995), Lectures on Conversation, Oxford: Blackwell.

Scott, M. and Lyman, S., (1968), 'Accounts', American Sociological Review, 33 (1): 46-62.

Strathern, M., (1999a), 'Criticizing best practice', History of the Human Sciences, 12 (4): 139-140.

Strathern, M., (1999b), Property, Substance and Effect: Anthropological Essays on Persons and Things, London: Athlone.

Strathern, M., (2000a), 'The tyranny of transparency', British Educational Research Journal, 26 (3): 309-321.

Strathern, M., (2000b), 'Introduction', in Marilyn Strathern (ed.), Audit Cultures: Anthropological studies in Accountability, Ethics and the Academy, 1-18, London: Routledge.

Strathern, M., (2002), 'Abstraction and decontextualisation: an anthropological comment', in Steve Woolgar (ed.), Virtual Society? Technology, Cyberbole, Reality, 302-313, Oxford: Oxford University Press.

Suchman, L., (1993), 'Technologies of accountability: of lizards and aeroplanes', in Graham Button (ed.), Technology in Working Order: Studies of Work, Interaction, and Technology, 113-126, London: Routledge.

Williams, R., (1973), 'Some political aspects of the Rothschild affair', Science Studies, 3 (1): 31-46.

Woolgar, S., (1990), 'Time and documents in researcher interaction: some ways of making out what is happening in experimental science', in Michael Lynch and Steve Woolgar (eds), Representation in Scientific Practice, 123-152. Cambridge, MA: MIT Press.

Woolgar, S., (1991), 'Configuring the user: the case of usability trials', in John Law (ed.), $A$ Sociology of Monsters: Essays on Power, Technology and Domination, 58-97, London, Routledge.

Yar, M., (2003), 'Panoptic power and the pathologisation of vision: critical reflections on the Foucauldian thesis', Surveillance and Society, 1 (3): 254-271. 